\title{
Oficina de maquete de relevo: um recurso didático
}

\author{
Romário Rosa de Sousa \\ Curso de Geografia, Inst. Ciências Humanas e \\ Sociais, UFMT, Barra do Garças, MT. \\ romarioufg@yahoo.com.br
}

\begin{abstract}
WORKSHOP ON MODEL OF RELIEF A DIDACTIC RESOURCE. This paper aims to help teachers on practical activities of developing a relief model for teaching-learning at the levels of basic education, high school, technical and undergraduate courses. The methodological procedures refer to seven stages, which are distributed both on theoretical and practical classes, as a didactic workshop. Data from the evaluation questionnaire reveals that all the 19 participants considered it good to attend the workshop on relief models. Considering the total of 19 participants, four have given a grade of 10 (ten); five have attributed grade 9 (nine); six, the grade 8 (eight); three evaluated as grade 7 (seven) and one gave a grade 6 (six). The students' formation, as critical readers of maps, is important to break the manipulation or domination that can be performed by cartographic documents, making the students become thinkers agents of the space . Citation: Sousa R.R.de. 2014. Oficina de maquete de relevo. Um recurso didático. Terræ Didatica, 10(1):22-28. <http://www.ige.unicamp.br/terraedidatica/> .
\end{abstract}

KEYWORDS: Workshop, model, relief, teaching-learning.

RESUMO Este trabalho teve como objetivo principal auxiliar os professores no ensino e aprendizagem de alunos do ensino fundamental, médio, técnico e de graduação, com aulas práticas de elaboração de uma maquete de relevo. Os procedimentos metodológicos pautaram-se em sete etapas distribuídas em aulas teórica e prática, na forma de oficina didática. A análise dos questionários de avaliação respondidos após a oficina revela que todos os 19 participantes responderam que foi bom ter participado. Do total de dezenove participantes, quatro deram nota 10 (dez); cinco atribuíram nota 9 (nove); seis, a nota 8 (oito); três deram 7 (sete) e um deu nota 6 (seis). A formação de alunos, como leitores críticos de mapas, é importante para romper com a manipulação ou dominação que pode ser realizada por meio dos documentos cartográficos, fazendo com que os educandos se transformem em agentes pensadores do espaço.

PALAVRAS-CHAVE: Oficina, maquete, relevo, ensino-aprendizagem. 


\section{Introdução e contexto}

$\mathrm{O}$ aluno que sabe compreender a realidade em que vive é capaz de estudar questões e espaços mais distantes e ter uma visão mais crítica da realidade (Callai 2000). Nessa linha de pensamento, a produção de um bom material didático, como maquetes, desempenha um papel importante como auxiliar dos professores, na organização de atividades de ensino, estimulando, assim, os alunos a pensar e interagir nas aulas, de forma dinâmica e participativa (Botelho 2005).

Didática e metodologias de ensino formam uma unidade, mantendo entre si relações recíprocas, cabendo ao professor desenvolver metodologia de trabalho própria, a fim de transmitir o conhecimento para os alunos. Dessa maneira, de acordo com (Libâneo 1994), o processo didático efetiva-se, a partir da mediação escolar, desenvolvendo os conteúdos e provocando a aprendizagem, o que tem como consequência, a formação do meio social. Castrogiovanni \& Goulart (2003) argumentam que, no ensino fundamental e médio, o livro didático não deve ser a única fonte de conhecimento, cabendo ao professor buscar outras fontes e diferentes maneiras de trabalhar suas aulas, de forma prazerosa e interessante. Deve ele fornecer, sim, aos alunos elementos que estimulem, a partir da prática da observação, a interpretação, a reflexão e a análise, construindo uma visão crítica da realidade e levando-o a sentir-se como agente transformador da sociedade.

O educador deve estar ciente de que, tratando-se da Geografia, podem ser utilizados inúmeros recursos didáticos e metodológicos, ou seja, usar das diferentes linguagens, entre elas, a geografia em canção, em atividades culturais, dramatização, debates, exploração e outros métodos. Uma característica importante do mundo atual é o desenvolvimento das chamadas tecnologias da comunicação e da informação. Por um lado, os avanços permitem simultaneidade, ou seja, tornam possível "presenciar" fenômenos naturais, astronômicos, políticos, sociais e outros. Mediante isso, o professor do ensino fundamental e médio e, até mesmo, universitário, pode usufruir de inúmeros meios tecnológicos para dinamizar suas aulas (Cavalcante 2008).

Para Castrogiovanni (2000) a maquete é um modelo tridimensional de espaço; é como um laboratório geográfico, onde as interações sociais do aluno, no seu dia a dia, são passíveis de serem percebidas, quase que na sua totalidade. A cons- trução da maquete é um dos primeiros passos para um trabalho mais sistemático das representações geográficas, tornando sua utilização, no auxílio ao ensino, uma técnica muito importante e boa para a compreensão do mundo geográfico.

A maquete pode ser estática ou dinâmica; a estática permite somente a observação dos elementos espaciais ali representados, já a maquete dinâmica permite, não somente a observação, como também a intervenção, levando os alunos a desenvolverem o senso crítico sobre aquilo que está sendo representado (Simieli 1991).

Atualmente, o que não falta em muitas escolas, tanto públicas quanto particulares, são recursos didáticos, como televisores, mapas, vídeos, documentários, aparelhos data-show, internet com sites específicos para professores e outros meios, que, quando utilizados com criatividade pelo professor, despertam o interesse dos alunos para o conteúdo aplicado, dando, assim, uma nova perspectiva ao ensino de Geografia. A esse respeito, Postuschka et al. (2007) concluem que textos escritos, de cartografia, relevo, astronomia, climatologia, rochas, minerais e as demais linguagens, juntos, aumentam para os alunos as oportunidades de entenderem o espaço geográfico e, consequentemente, fica mais fácil entender o mundo em que vivem.

Para Almeida (2008), a cartografia escolar vem se estabelecendo na interface entre cartografia, educação e geografia, de maneira que os conceitos cartográficos tomam lugar no currículo e nos conteúdos de disciplinas voltadas para a formação de professores. Com isso, todos os educadores concordam que aprender a ler um mapa é necessário para a formação básica dos educandos; dessa forma, cabe ao professor buscar metodologias interessantes para obter a participação dos alunos nas aulas.

O professor de Geografia pode usufruir das cartas topográficas, de diversas formas, como fonte de informação fácil e dinâmica, para tornar suas aulas atrativas e participativas; uma alternativa é a utilização das curvas de nível para a elaboração de maquetes de relevo.

\section{Objetivos}

O presente trabalho teve como objetivo principal auxiliar os professores no ensino e aprendizagem de alunos do ensino fundamental, médio, técnico e de graduação, com aulas práticas de elaboração de uma maquete de relevo. 


\section{Materiais, métodos e técnicas}

O Estado de Mato Grosso está localizado entre as coordenadas geográficas de latitudes $7^{\circ}$ a $18^{\circ}$ a sul do equador e longitudes $50^{\circ}$ a $62^{\circ}$ oeste de Greenwich. As altitudes variam de 100 a 1200 metros, no centro do Continente Sul Americano. A escolha da área foi definida entre as coordenadas UTM de longitude 360000 a 380000 e de latitude 8260000 a 8244000 no perímetro da cidade de Barra do Garças (MT), localizada às margens do Rio Araguaia, no estado de Mato Grosso, na divisa com o estado de Goiás (Fig. 1). As ilustrações que acompanham o artigo foram elaboradas pelo autor em 2012.

Assim, a área escolhida faz parte do Parque Estadual da Serra Azul e apresenta um relevo interessante: anfiteatros, nascentes, cachoeiras, áreas de risco (sujeitas a inundações e erosão), uso e ocupação do solo e impactos ambientais e vegetação de encosta. Com o objetivo principal de auxiliar no ensino e aprendizagem, os procedimentos metodológicos pautaram-se em sete etapas:

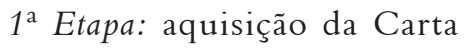
Topográfica IBGE, Folha Barra do

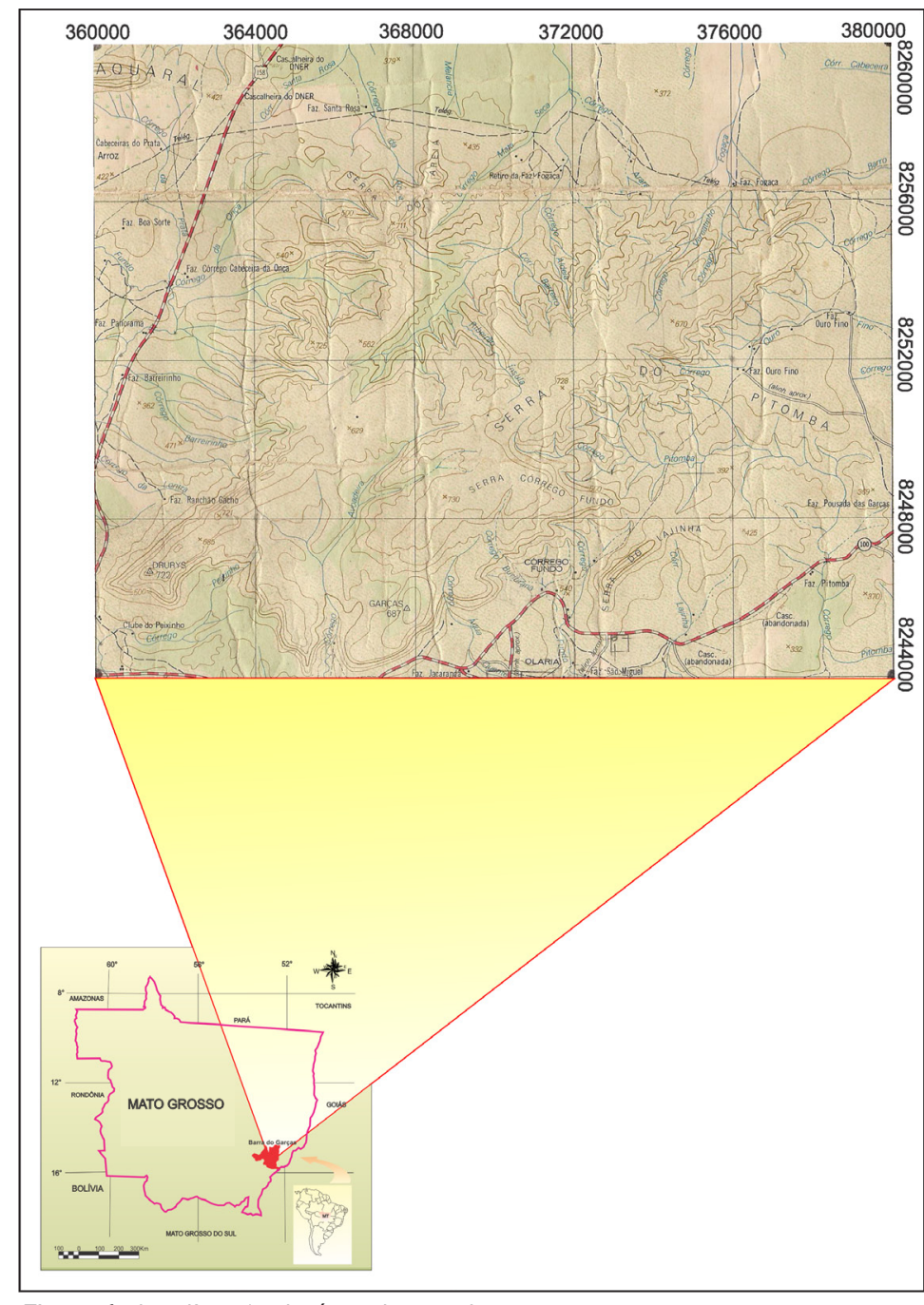

Figura 1: localização da área de estudo
Garças (MT), código internacional SD.22-Y-D-IV MI-2206 escala 1:100.000, equidistância das curvas de nível de $50 \mathrm{~m}$;

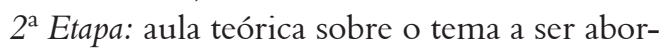
dado;

$3^{a}$ Etapa: aquisição dos materiais de baixo custo;

$4^{a}$ Etapa: ampliação da área escolhida, a partir da escala 1:100.000 para 1:20.500 aproximadamente, de escala horizontal; já a escala vertical foi definida em 1:5.000. A ampliação foi realizada em software da linha Corel; posteriormente, a impressão foi efetuada no formato A0;

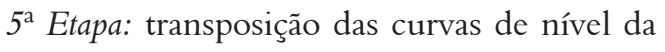
área escolhida para folhas de isopor;

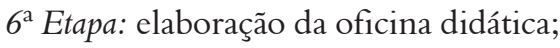

$7^{\text {a }}$ Etapa: aplicação de um questionário avaliativo e quantitativo para se mensurar a aceitação da oficina.

Para o desenvolvimento da oficina pedagógica fez-se uso dos materiais listados na Tabela 1):

\section{Metodologia}

Após a ampliação da área escolhida da carta topográfica, foi feita a impressão em um banner medindo $1,17 \mathrm{~m} \times 100 \mathrm{~cm}$, em papel sulfite, 75 gramas no formato A0, contendo as curvas de nível. Os participantes formaram grupos de seis pessoas, e, para cada grupo, na qual foi dada a incumbência para a realização de uma etapa de trabalho, durante a oficina. Assim, um grupo foi instruído a fixar os carbonos/ filme, com fita durex, na parte de trás do banner, para que pudesse passar as curvas de nível para as folhas de isopor. Enquanto isso, outro grupo selecionou as folhas de isopor e emendou as que eram necessárias. Posteriormente, o banner foi afixado nas folhas de isopor, de modo que ficou sobreposto; a partir daí, o trabalho foi de passar o lápis sobre os contornos 
das curvas de nível, com firmeza, de modo que ficou uma cópia delas no isopor (Fig. 2). Posteriormente a essa etapa, outro grupo começou a realizar os cortes das folhas de isopor, com agulha aquecida em uma vela de parafina, de modo que cada curva de nível se referia a uma altitude (Fig. 3).

$\mathrm{Na}$ sequência, foram cortadas todas as curvas de nível, ou seja, cada curva de nível em uma folha de isopor separada, correspondente, cada uma, a um intervalo de altitude determinado, totalizando uma quantia de nove folhas de isopor, trabalhadas

Tabela 1. materiais utilizados na oficina

\begin{tabular}{|c|c|}
\hline Quantidade & Descrição \\
\hline 15 & alfinete com cabeça grande \\
\hline 05 & $\begin{array}{l}\text { bisnaga de corente solúvel em água nas } \\
\text { cores azul, preto, amarelo, vermelho, } \\
\text { verde }\end{array}$ \\
\hline 01 & caixa de fósforo \\
\hline 01 & $\begin{array}{l}\text { caneta de escrever em cd-rom, ponta } \\
\text { grossa }\end{array}$ \\
\hline 15 & carbono filme \\
\hline 01 & carta topográfica na escala 1:100 000 \\
\hline 10 & copo plástico de $100 \mathrm{ml}$ \\
\hline 01 & fita crepe larga transparente de $5 \mathrm{~cm}$ \\
\hline 10 & $\begin{array}{l}\text { folha de isopor, medindo } 50 \times 100 \mathrm{~cm} \text { de } \\
\text { tamanho e } 1 \mathrm{~cm} \text { de espessura }\end{array}$ \\
\hline 06 & folha de lixa $n^{\circ} 50$ \\
\hline 01 & $\begin{array}{l}\text { galão de 3,600 litros de massa corrida } \\
\text { PVA }\end{array}$ \\
\hline 01 & galão de 3,600 litros de tinta branca látex \\
\hline 02 & kilograma de jornal \\
\hline 01 & $\begin{array}{l}\text { litro de verniz transparente para pintar } \\
\text { madeira }\end{array}$ \\
\hline 01 & $\begin{array}{l}\text { novelo lã de crochê com } 125 \mathrm{~m} \text { na cor } \\
\text { azul claro }\end{array}$ \\
\hline 10 & palito de palitar dentes \\
\hline 04 & parafuso $8 \mathrm{~mm}$ com porca \\
\hline 03 & pincel de pinturas em tecido \\
\hline 01 & $\begin{array}{l}\text { placa espessa de madeira medindo } \\
100 \mathrm{~cm} \times 80 \mathrm{~cm}\end{array}$ \\
\hline 20 & prego medindo 10 x 15 de bitola \\
\hline 04 & $\begin{array}{l}\text { sarrafo de madeira medindo } 2 \mathrm{~cm} \times 2 \mathrm{~cm} \\
\text { de largura e } 90 \mathrm{~cm} \text { de comprimento }\end{array}$ \\
\hline 01 & tesoura \\
\hline 02 & tubo de cola branca escolar $500 \mathrm{~g}$ \\
\hline 10 & $\begin{array}{l}\text { tubo de cola de colar isopor de } 80 \mathrm{~g} \text { não } \\
\text { tóxica e lavável em água corrente }\end{array}$ \\
\hline 03 & vela de parafina \\
\hline
\end{tabular}

Organizador: Romário Rosa de Sousa (2013).

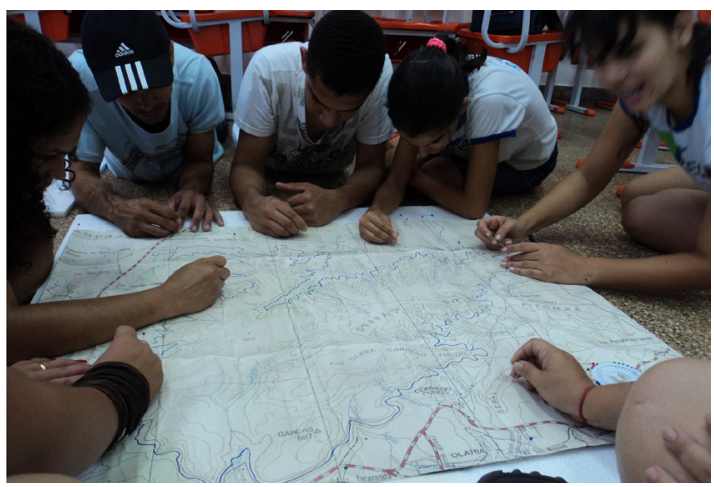

Figura 2. processo de passar as curvas de nível para o isopor

uma a uma. Depois dos cortes nas folhas de isopor representando intervalos de nível, ambas foram montadas e coladas, uma em cima da outra, das menores altitudes para as maiores, dando forma à maquete, em cima da placa espessa de madeira Figs. 4 e 5.

Após a etapa de cortes, montagem e colagem, foi necessário lixar as folhas de isopor para retirar as arestas mais agudas, suavizando, ao máximo possível, os saltos artificiais do relevo e dando uma forma mais natural aos relevos representados na maquete.

Dando continuidade à elaboração da oficina, utilizou-se massa corrida PVA, com água e pincel, para corrigir as imperfeições do relevo e suavizar as variações de altura de uma folha de isopor para a outra. Após secagem da massa corrida na maquete, efetuou-se análise criteriosa de observação, na carta topográfica, sobre as formas do relevo da área em questão.

O próximo passo foi à pintura da maquete, quando, de acordo com a altitude, elaborou-se o jogo de cores. Dessa forma para a representação do relevo, nas placas de isopor com altitudes maiores, foram usadas as cores quentes (amarelo, laranja,

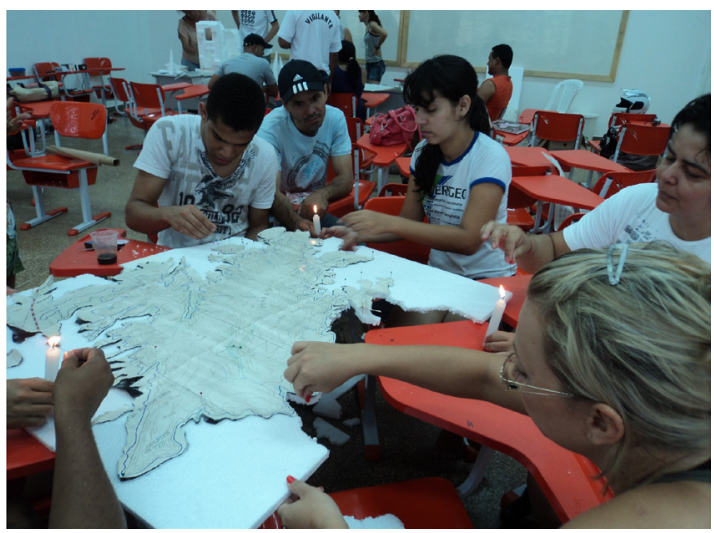

Figura 3. cortes das curvas de nível para o isopor 


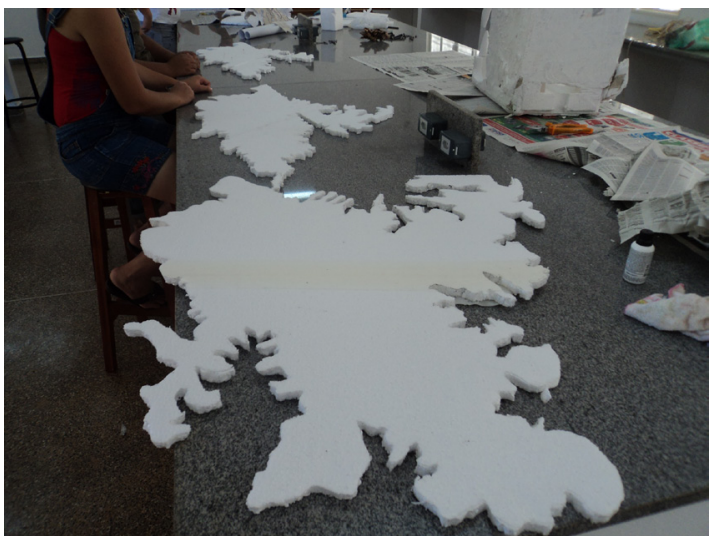

Figura 4: curvas de nível cortadas

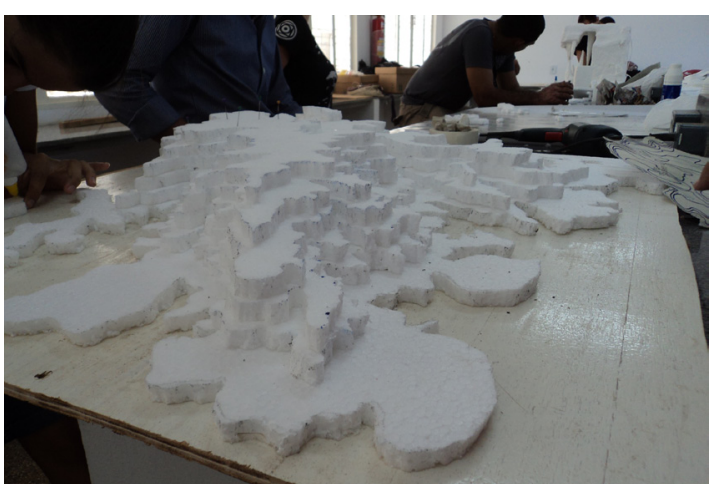

Figura 5: montagem e colagem da maquete.

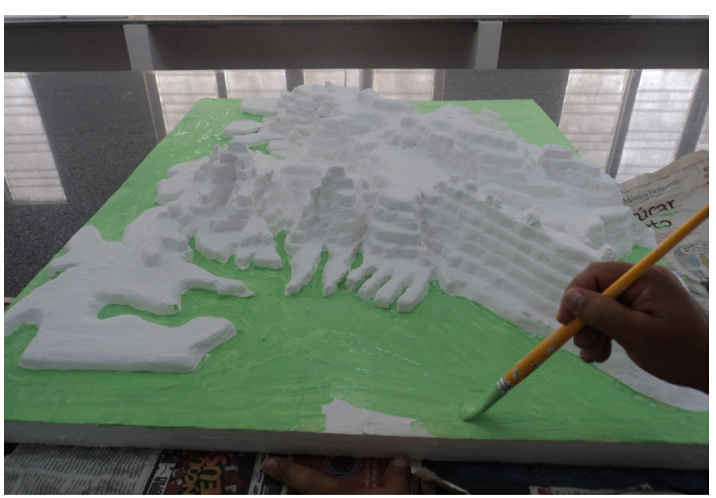

Figura 6: pintura das curvas de nível

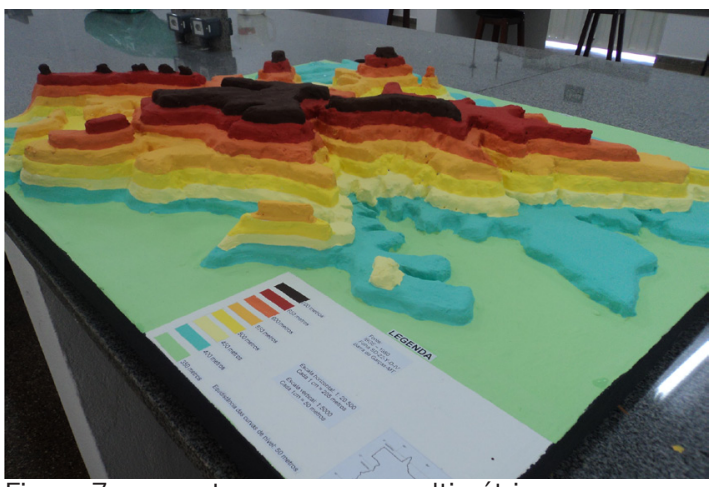

Figura 7: maquete com as cores altimétricas. vermelho e marrom) e, para as menores altitudes, utilizaram-se as cores frias (violeta, azul e verde) (Figs. 6 e 7); dessa forma, cada cor representa um intervalo de cota altimétrica.

Para Martinelli (2009), o resultado é a representação do relevo, em escala pequena, por curvas de nível, selecionadas convenientemente, entre as quais se acrescenta uma gama de cores, em ordem visual crescente, das mais claras às mais escuras, acompanhando a progressão para o alto das cotas de altitude. Essa elaboração dará ao relevo uma visão de conjunto da imagem de sua configuração plástica. Trata-se de um mapa morfométrico do relevo, caracterizando-o, em suas relações quantitativas, junto às faixas de altitude, porém, em termos de visualização, obter-se-á apenas a expressão da informação de nível ordenado, não possibilitando a avaliação quantitativa, a noção do quanto de altitude será obtido pela leitura da legenda.

Depois da fase de colorir a maquete, efetuou-se a colagem da legenda e os retoques finais. Posteriormente, passou-se o verniz para impermeabilizar a maquete, aumentando sua durabilidade e resistência (Fig. 8).

Com a maquete já construída, o professor poderá utilizá-la de várias formas, para dinamizar as suas aulas e torná-las mais atraentes, ao mesmo tempo em que permite uma interação entre os alunos e ele mesmo.

É importante ressaltar que, para o educador realizar a elaboração da oficina de maquete de relevo, em sua unidade escolar, é necessário que ele seja acompanhado por mais um adulto, porque, durante trabalhos da oficina, será necessário manusear objetos que se aquecem e são pontiagudos, e que, portanto, oferecerem certo perigo de queimar, cortar e perfurar o corpo humano. Assim, sugere-se que o professor comunique aos alunos dos riscos inerentes à atividade e que supervisione de muito perto o trabalho dos grupos, contando com colegas de outras turmas para esta supervisão.

Espera-se que, metodologicamente, as pessoas envolvidas neste trabalho passem a ser agentes transformadores e divulgadores da metodologia, em um processo de formação dinâmica, em que haja o envolvimento permanente e participativo para o exercício do papel de cidadão.

\section{Discussão e interpretação de resultados}

O relevo é o conjunto de saliências e reentrâncias que compõem a superfície terrestre. É um componente da litosfera relacionado com o conjunto 


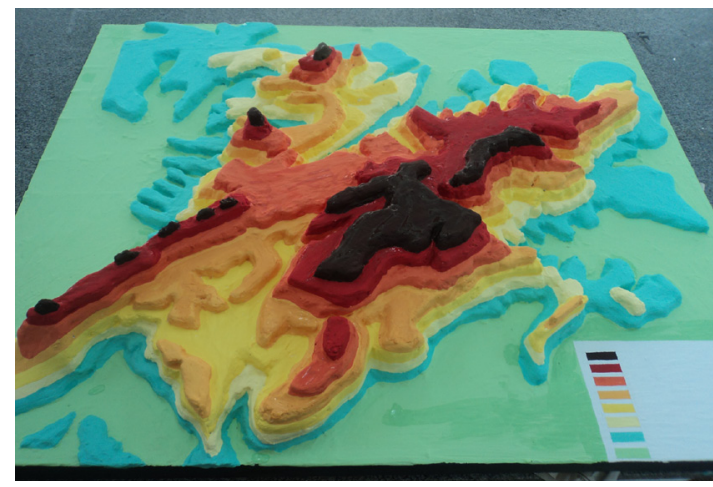

Figura 8: maquete pronta para uso.

rochoso subjacente e com os solos e sedimentos que o recobrem. Caracteriza-se por elevações e depressões de diferentes formas como: horizontais, tabulares, convexas, côncavas, angulares e escarpadas que constituem o relevo (Florenzano 2008). Com isso os processos morfogenéticos são responsáveis pela esculturação das formas de relevo, representando a ação da dinâmica externa sobre as vertentes (Crhistofoletti 1980).

Na representação do relevo em curvas de nível, foi feita representação em mapa pelo método isarítmico (curvas de nível) (Martinelli 2009). Na construção de um mapa com a aplicação do método asarítmico consideramos que cada valor que exprime a intensidade do fenômeno, tomado em pontos localizados e identificados em (X, Y) sobre a base cartográfica, constitui uma terceira dimensão (Z), com isso o conjunto desses pontos com valor $Z$ será visto como uma superfície tridimensional contínua, onde usa representação no plano do mapa é a projeção ortogonal das linhas, interseções da superfície com planos paralelos e equidistantes ao primeiro.

Passini (1989) sugere que uma das melhores maneiras de se trabalhar a cartografia escolar, no ensino fundamental e médio, é a partir de atividades de leituras dos mapas e cartas topográficas, estimulando os educandos a realizarem trabalhos interativos e jogos que visem à sua participação, em grupo; sendo assim, a elaboração de oficinas didáticas de relevo é apenas uma das várias metodologias possíveis de se trabalhar em sala de aula. Isso porque as cartas topográficas trazem consigo uma série de simbologias e uma grande variedade de informação, dentre elas, as curvas de nível, que representam a cópia mais fiel das configurações de relevo que compõem a superfície terrestre.

Participaram do desenvolvimento da oficina didática de elaboração de maquete de relevo, aproximadamente, dezenove acadêmicos, no ano de 2011, do Curso de Geografia do Campus Universitário do Araguaia da UFMT. Foi perguntado no questionário de avaliação sobre o nível de aceitação na oficina. Do total de dezenove acadêmicos, cinco disseram que a oficina está excelente; nove ótimo; cinco bom; nenhum avaliou como regular ou ruim. Observando os questionários avaliativos, verifica-se que todos os dezenove participantes responderam que foi bom ter participado da oficina de maquete de relevo, dentro do espaço universitário, como uma forma didática de ensino e todos ficaram interessados por saber que elaboração de maquetes de relevo é algo tão envolvente e criativo.

Os participantes da oficina demonstraram-se interessados pela metodologia, de forma satisfatória, fazendo perguntas e sanando dúvidas a todo o momento, por estarem aprendendo sobre relevo e cartografia de uma maneira diferente. Dezoito participantes da oficina responderam no questionário avaliativo que as explicações durante a realização da oficina de maquete serviram para melhorar o entendimento em outras áreas do conhecimento da Geografia. Em contrapartida, um participante respondeu que não houve um entendimento. Do total de dezenove participantes, quatro deram nota 10 (dez); cinco foram nota 9 (nove); seis atribuíram a nota 8 (oito); três deram 7 (sete) e um deu a nota 6 (seis) (Tab. 2).

Tabela 2. Notas atribuídas após realização da oficina.

\begin{tabular}{c|c}
\hline Nota & Quantidade de participantes \\
\hline 10 & 04 \\
\hline 9 & 05 \\
\hline 8 & 06 \\
\hline 7 & 03 \\
\hline 6 & 01 \\
\hline
\end{tabular}

Organizador: Romário Rosa de Sousa (2013).

Os participantes argumentaram, de forma escrita, que a elaboração da oficina de maquete de relevo deve continuar a ser desenvolvida no ano de 2012, e que a atividade é de grande valia para os professores e alunos; também afirmaram que a aula fica mais prazerosa, e que eles se interessam por esse tipo de aula prática, onde o aprendizado fluiu de maneira interessante e melhor, não só na área da Geografia, mas também na Matemática, da Física, da Biologia, da Química e outras.

Segundo Lima (2007), os mapas estão presentes ao longo de todo o ensino da Geografia. Se eles estão presentes, durante a vida escolar (e também cotidia- 
na) das pessoas, e são compreendidos como instrumentos geográficos, transmissores de determinadas informações, eles não podem ser vistos e utilizados apenas como ilustrações do texto; acredita-se na possibilidade de o mapa contribuir mais do que isso, auxiliando o aluno na compreensão de fenômenos geográficos, sendo que, muitas vezes, o simples mapa é capaz de transmitir o conhecimento geográfico, não sendo preciso um texto escrito para explicá-lo, mas, para isso, é necessário que o educador seja dinâmico e interessado em lecionar os conteúdos da Geografia, de forma clara e instigante.

\section{Considerações Finais}

Observou-se que todos os participantes da oficina ficaram interessados pelas atividades das aulas práticas, e que ela proporcionou, de forma excelente, a integração entre todos. Acredita-se que a oficina de maquete de relevo é um recurso didático, de fato efetivo como metodologia para auxiliar no ensino e aprendizagem para professores, alunos do ensino fundamental, médio, técnico e de graduação, com aulas práticas.

A formação de alunos, como leitores críticos de mapas é importante para romper com a manipulação ou dominação que pode ser realizada por meio dos documentos cartográficos, fazendo com que os educandos se transformem em agentes pensadores do espaço. Entende-se que somente um leitor crítico de mapas será capaz de não se iludir com a representação visual, pois será capaz de compreendê-la dentro do processo de comunicação, que expressa a visão de mundo.

Daí a importância da Geografia, como ciência humana voltada para analisar e interpretar o espaço, cabendo ao professor trabalhar, de maneira interessante, as suas aulas, despertando nos alunos o interesse e o gosto pelos conteúdos ministrados pela Geografia.

\section{Referências}

Almeida, R. D. 2008. Cartografia escolar. São Paulo: Contexto.
Botelho L.A.I., Silveira J.S., Andrade S.N. 2005. Belo Horizonte, Cadernos de geografia, 25(15):60-76. $2^{\circ}$ semestre 2005.

Callai H.C. 2003. O ensino de geografia: recortes espaciais para análise. In: Castrogiovanni A.C., Callai H.C., Schaffer N.O., Kaercher N.A. orgs. 2003. Geografia em sala de aula, práticas e reflexóes. $4^{\mathrm{a}}$ ed. Porto Alegre: Mediação p. 57-63.

Castrogiovanni A.C. org. 2000. Ensino de geografia: práticas e textualizações no cotidiano. Porto Alegre: Mediação.

Castrogiovanni A.C., Goulart L.B. 2003. A questão do livro didático em Geografia: elementos para uma análise. In: Castrogiovanni A.C., Callai H.C., Schaffer N.O., Kaercher N.A. orgs. 2003. Geografia em sala de aula, práticas e reflexões. $4^{\mathrm{a}} \mathrm{ed}$. Porto Alegre: Mediação. p. 133-171.

Cavalcante L.S.de. 2008. A geografia escolar e a cidade: ensaios sobre o ensino de geografia para a vida urbana cotidiana. Campinas: Papirus.

Christofoletti A. 1980. Geomorfologia. São Paulo: Blücher.

Florenzano T.G. org. 2008. Geomorfologia: conceitos e tecnologias atuais. São Paulo: Ofic. Textos.

Libâneo J.C. 1994. Didática. São Paulo: Cortez. (Col. Magistério $2^{\circ}$ grau, série Formação do Professor).

Lima G.R.C.P. 2012. O tesouro dos mapas. A cartografia dos livros didáticos de geografia do ensino fundamental. Campinas: Inst. Geoc. Unicamp. 179p. (Dissert. Mestr.). URL: http://libdigi.unicamp.br. Acesso junho 2012.

Martinelli M. 2009. Relevo do Estado de São Paulo. França: Confins, 7(7). 2009. URL: http://confins.revues.org/6168\# tocto2n3. Acesso em junho 2012.

Martinelli, M. 2009. Mapas da Geografia e cartografia temática. São Paulo: Contexto.

Passini, E. Y. 1989. Espaço: percepção e representação: o tratamento de representações do espaço no livro didático. São Paulo: USP. (Dissert. Mestr.).

Pontuschka N.N, Paganelli T.I., Cacete N.H. Para ensinar e aprender geografia. São Paulo: Cortez, 2007.

Silva C.M., Ferreira G.C. 2008. Produção de material didático: jogo das curvas de nível. Goiânia: Bol. Goiano de Geogr., 28(2):157-170.

Simieli M.E.R. O uso de plantas e mapas na escola de $1^{\circ}$ grau: ênfase para as séries iniciais. In: Projeto Ensino da cidade de São Paulo. São Paulo: Assoc. Geógr. Bras., 1991, p. 24-40 